\title{
Plasma protein concentration in nutritional assessment
}

By Yvon A. Carpentier, Jean Barthel and Jean Bruyns, Department of Surgery and Laboratory of Experimental Surgery, Hôpital Universitaire SaintPierre, Free University of Brussels, 322, rue Haute, 1000 Brussels, Belgium

It is generally assumed that all the proteins of the body have a function. This assumption implies that, although some proteins could be more labile (Munro, I970), there is no real protein reserve. Therefore, the main aim of clinical nutrition is either to protect or to restore the size of the body protein compartment.

The parameters that have been used for assessing the nutritional status of a subject and/or the efficiency of nutritional therapy are anthropometric measurements, urinary excretion of muscular protein catabolites, total body nitrogen, nitrogen balance, turnover of various proteins and plasma concentration of some proteins.

Measurement of the muscular circumference of the non-dominant arm is easy to perform and to repeat. However, the wide range of normal values restricts its use for monitoring mid- and/or long-term variations in a given individual. In these conditions, this parameter seems adequate for indicating changes in the skeletal muscle compartment. These changes can also be studied by determining the urinary excretion of 3 -methylhistidine, but the value of the information could be more qualitative than quantitative.

Measurements of total body nitrogen and lean body mass can be very accurate. However, they require sophisticated equipment that is available only in some highly specialized research units and are, therefore, not applicable in clinical routine. The determination of nitrogen balance does not require sophisticated equipment and can be repeatedly performed in a given patient; however, it is a tedious, time-consuming and therefore expensive procedure. The above-mentioned parameters are used to measure the size (or the variations) of a pool representing several different protein compartments, each one having at least one specific function. Because of their large size, the muscular and the visceral tissue compartments play a predominant role in these measurements. However, the functional importance of the various body proteins can differ according to the clinical condition of a patient.

This latter point emphasizes the interest in measuring the turnover of various proteins. These dynamic determinations clearly separate the rates of synthesis and breakdown for each of the studied proteins. However, the use of radioactive isotopes imposes some obvious limitations for investigating human subjects.

The determinations of many plasma proteins is an easy and rapid procedure that can be repeatedly performed. Plasma visceral proteins-such as albumin, transferrin (TSF), thyroxin-binding pre-albumin (TBPA) and retinol-binding protein (RBP) - have important functions as hormone, substrate and vitamin 
carriers. These functions are relatively well protected during starvation when amino acids released by protein catabolism in peripheral muscles are directed towards the liver for the purpose of gluconeogenesis and also for the synthesis of these proteins. Other plasma proteins such as the acute-phase reactants$\alpha$-I-glycoprotein, $\alpha$-I-antitrypsin, $\quad$-reactive protein, $\alpha$-2-macroglobulin, haptoglobin, caeruloplasmin, fibrinogen, etc.-play an important role in the defence of the host during various inflammatory conditions. Their synthesis in the liver is markedly stimulated by the leucocyte endogenous mediator (Pawanda \& Beisel, I982). They then stimulate the development of the immune response and participate in wound healing.

The plasma concentration of a protein is affected not only by the balance between the rates of synthesis and breakdown, but also by changes in the amount and distribution of body fluids, by changes in capillary permeability, by external losses and by the lymphatic return (Fleck, 1981 ). It was recently emphasized that the plasma concentration of albumin, although widely used in nutritional assessment and demonstrated to be a predominant factor in prognostic indices (Mullen et al. 1980), is much more affected by changes in body fluids, occurring for instance after injury, than by protein depletion. Therefore, this parameter appears to be adequate only for studying long-term variations in the nutritional status of a given subject.

Rapid turnover visceral proteins, such as TBPA and RBP, have been proposed for investigating short-term effects of nutritional therapy (Large et al. 1980). The early scientific interest in these proteins was focused on their relationship with vitamin $A$ and thyroid hormone metabolism (Surks \& Oppenheimer, I964; Goodman, 1979; Rask et al. 1980). It was later demonstrated that their plasma level was very low during protein depletion and rapidly increased after correction of the nutritional deficit (Ingenbleek et al. 1975; Shetty et al. 1979; Young et al. 1979). A transient decrease in the plasma level of these proteins was described in inflammatory conditions that are met after injury (Ramsden et al. 1978) and during sepsis (Cooper \& Ward, 1979). These proteins were also shown to decrease during the 3 months preceding the death of patients with colon-rectum cancer (Milano et al. 1978). However, the role played by nutrition in these circumstances was not clearly established.

The purpose of the present paper is to discuss:

I. The relationship between the rapid turnover proteins (TBPA and RBP) and slow turnover visceral proteins (albumin and TSF) and some acute-phase reactants ( $\alpha$-I-glycoprotein and $\alpha-\mathrm{I}$-antitrypsin) in non-injured patients

2. The early effect of nutritional support on the plasma level of these plasma proteins

3. The effect of surgery on the plasma level of these plasma proteins

\section{Material and methods}

Selection of the patients. The relationship between the plasma concentration of 
Table I. Clinical and biological status of the patients

(Mean values with their standard errors)

\begin{tabular}{|c|c|c|c|c|c|c|c|c|c|c|}
\hline & & & & & & & lasma con & acentratic & & \\
\hline & $n$ & Male & Female & $\begin{array}{c}\text { Age } \\
\text { (years) }\end{array}$ & $\begin{array}{l}\text { ALB } \\
(\mathrm{g} / \mathrm{l})\end{array}$ & $\begin{array}{c}\text { TSF } \\
(\mathrm{mg} / \\
\text { I00 } \mathrm{ml})\end{array}$ & $\begin{array}{c}\text { TBPA } \\
\text { (\% pre- } \\
\text { dicted } \\
\text { value) }\end{array}$ & $\begin{array}{c}\text { RBP } \\
\text { (\% pre- } \\
\text { dicted } \\
\text { value) }\end{array}$ & $\begin{array}{c}\alpha-\mathrm{I}-\mathrm{GP} \\
(\mathrm{mg} / \\
\mathrm{I} 00 \mathrm{ml})\end{array}$ & $\begin{array}{c}\alpha-\mathrm{I}-\mathrm{AT} \\
(\mathrm{mg} / \\
100 \mathrm{ml})\end{array}$ \\
\hline Cancer patients & I6 & I0 & 6 & $64 \cdot 6$ & $3^{6 \cdot 6}$ & 245 & 99 & I IO & 70 & 256 \\
\hline Non-cancer patients & 18 & 13 & 5 & $5^{I \cdot 1}$ & $32 \cdot 4$ & $19^{I}$ & 54 & $5^{8}$ & 74 & $26_{3}$ \\
\hline Total & 34 & 23 & I I & $\begin{array}{c}57 \cdot 4 \\
( \pm 2 \cdot 8)\end{array}$ & $\begin{array}{c}34 \cdot 4 \\
( \pm 1 \cdot 2)\end{array}$ & $\begin{array}{c}223 \\
( \pm 20)\end{array}$ & $\begin{array}{c}75 \\
( \pm 7)\end{array}$ & $\begin{array}{c}82 \\
( \pm 7)\end{array}$ & $\begin{array}{c}73 \\
( \pm 7)\end{array}$ & $\begin{array}{c}26 I \\
( \pm 2 I)\end{array}$ \\
\hline
\end{tabular}

ALB, albumin; TSF, transferrin; TBPA, thyroxin-binding pre-albumin; RBP, retinol-binding protein; $\alpha$-I-GP, $\alpha$-I-glycoprotein; $\alpha$-I-AT, $\alpha$-I-antitrypsin.

various proteins was studied in a group of thirty-four cancer-bearing and noncancer patients requiring total parenteral nutrition (TPN) on clinical grounds. The criteria of exclusion were impaired hepatic function, renal failure, insulindependent diabetes, disseminated malignancy and recent transfusion of blood and/or albumin. The clinical status and the plasma concentration of albumin, TSF, TBPA, $\alpha$-I-glycoprotein and $\alpha$-I-antitrypsin are shown in Table I. Because of the influence of age and sex on the plasma levels of TBPA and RBP, these parameters are presented as percentages of the predicted normal values corrected for these factors.

Because of the influence of some tumours on the efficacy of nutritional support, the effect of TPN on plasma visceral proteins was studied in two groups of noncancer bearing patients considered to be protein-depleted on the basis of an initial plasma albumin level below $35 \mathrm{~g} / 1$ and a rapid turnover protein concentration below $80 \%$ of the predicted values.

The first group consisted of fifteen patients (twelve males and three females) with normal hepatic and renal function. The mean age of these patients was $47 \pm 4$ years. The diagnoses were inflammatory bowel disease $(n-5)$, upper gastrointestinal tract fistulae $\left(n_{3}\right)$, prolonged small bowel dysfunction $\left(n_{3}\right)$, chronic pancreatitis with cyst $\left(\begin{array}{l}n 2 \\ 2\end{array}\right)$, acute colonic diverticulitis $\left(n_{\mathrm{I}}\right)$ and portal vein thrombosis $\left(n_{\mathrm{I}}\right)$. These patients received, for at least I week, TPN providing $125 \%$ of their energy expenditure (either estimated from the Harris-Benedict formula or measured by indirect calorimetry using a Beckman MMC gas exchange analyser). The nitrogen-energy ratio was $\mathrm{I} g / 630 \mathrm{~kJ}$. The non-protein energy intake was provided in approximately equal amounts by glucose and exogenous fat (Intralipid, Kabivitrum).

The second group consisted of fourteen patients with acute renal failure but normal liver function. The plasma urea concentration was above $200 \mathrm{mg} / 100 \mathrm{ml}$ and the plasma creatinine concentration was above $3 \mathrm{mg} / \mathrm{I} 00 \mathrm{ml}$. Nine patients (four males; five females) with preserved diuresis volume did not require dialysis. The mean age was $68 \cdot I^{ \pm} 3.4$ years. Five patients (three males; two females) 
presented oliguria and required recurrent haemodialysis. The mean age of these patients was $48 \cdot 6+6 \cdot 2$ years. These patients received, for at least $9 \mathrm{~d}$, TPN providing a daily intake of $4.4 \mathrm{~g}$ nitrogen as essential amino acids plus arginine and histidine (ProteinSteril KE Nephro, Fresenius), $300 \mathrm{~g}$ of glucose and $100 \mathrm{~g}$ of exogenous fat (Intralipid, Kabivitrum). RBP is catabolized mainly in the kidneys so the determination of its concentration is irrelevant in patients with renal failure and will not be presented in the results.

The effect of surgery on the plasma concentration of visceral and acute-phase proteins was prospectively studied in two groups of patients undergoing standardized operations on the gastrointestinal tract. Oral nutrition was compromised for the first 3 post-operative days in each case; during that period, the patients were infused daily with $2.5-3.01$ of $5 \%$ dextrose in water (plus electrolytes). Oral nutrition was then progressively re-initiated and resumed to normal on the 6 th or 7 th post-operative day.

The first group consisted of ten patients (nine males; one female) undergoing elective surgery. The mean age in this group was $48 \cdot 7 \pm 4.7$ years. Six patients underwent a Billroth II type of gastrectomy either for benign antral or stenosing duodenal ulcer. Three patients underwent a right hemicolectomy, in two instances for Dukes'A cancer of the caecum and in one case for benign caecal angioma. One patient underwent a resection of the small bowel for obstruction. None of these patients developed any post-operative complications.

The second group consisted of fourteen patients (eleven males; three females) undergoing emergency surgery. The mean age in this group was $39 \cdot 7 \pm 4 \cdot 4$ years. Five patients underwent a Billroth II type gastrectomy for a bleeding duodenal ulcer; five patients underwent the suture of a perforated duodenal ulcer completed by a proximal vagotomy; two patients underwent a splenectomy and sutures of the intestine after injury; two patients underwent multiple small bowel resection. Twelve patients of this group had an uncomplicated post-operative course; two patients developed an abdominal abscess that could, however, be drained without necessitating another laparotomy.

Biological determinations. Plasma albumin concentration was determined by protein electrophoresis. The plasma concentration of TSF, TBPA, RBP, $\alpha-1-$ glycoprotein, $\alpha$-I-antitrypsin and C-reactive protein was determined by nephelometry using an automated Technicon Analyzer.

Statistical analysis. Statistical analysis was performed using the least-squares method for the correlation between plasma proteins concentration and Student's paired $t$ test for the evolution of protein levels.

\section{Results}

Inter-relation between plasma proteins concentrations. A significant positive correlation $(r \circ 73 ; P<0.01)$ was found between the plasma levels of the slow turnover visceral proteins albumin and TSF (Fig. 1). A significant positive correlation was also observed between the plasma levels of TBPA and albumin 


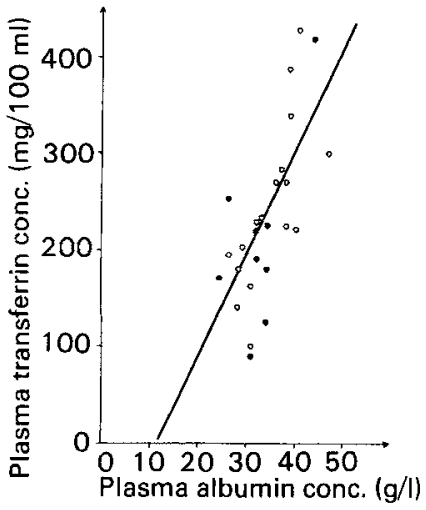

Fig. I. Plasma transferrin v. plasma albumin concentrations before starting total parenteral nutrition. (O), Non-cancer patients $(n$ I I ); $(O)$, cancer patients $(n$ I 7$) \cdot y=-126 \cdot 18+106 \cdot 26 x$ $(r 0.73 ; P 0.01)$.

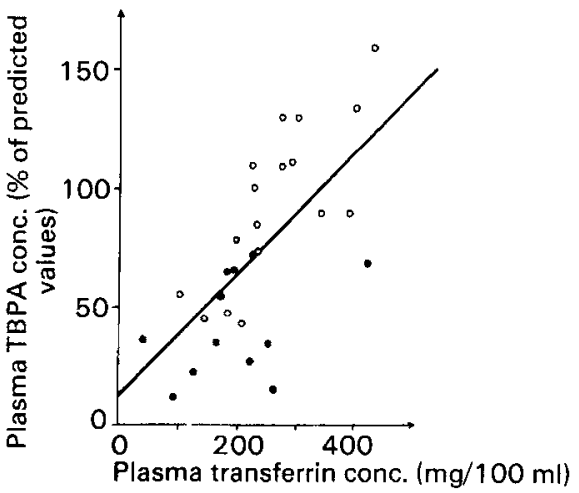

Fig. 3. Plasma thyroxin-binding pre-albumin (TBPA) v. plasma transferrin concentrations before starting total parenteral nutrition. (O), Non-cancer patients $\left(n \mathrm{I}_{2}\right) ;(0)$ cancer patients $\left(\begin{array}{ll}n & \mathrm{I} 6) .\end{array}\right) \quad y=\mathrm{I} \mathrm{I} \cdot 86+0.26 \times(r 0.63$; P o.0I).

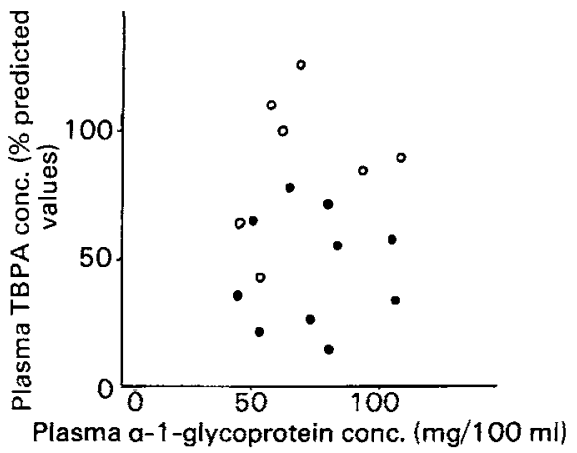

Fig. 5. Plasma thyroxin-binding pre-albumin (TBPA) v. plasma $\alpha$-I-glycoprotein. (O), Noncancer patients ( $n$ IO); $(O)$, cancer patients $(n 7)$. ( $r 0.04$; not significant.)

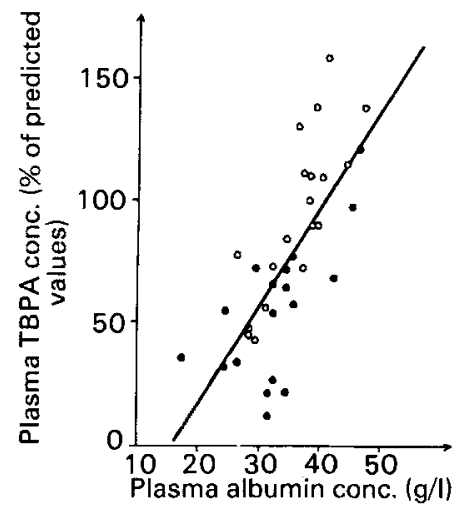

Fig. 2. Plasma thyroxin-binding pre-albumin (TBPA) $v$. plasma albumin concentrations before starting total parenteral nutrition. (O), Non-cancer patients ( $n \mathrm{I} 8) ;(0)$, cancer patients ( $\left.\begin{array}{ll}n & \mathrm{I} 9\end{array}\right), y=-6 \mathrm{I} \cdot 55+39.8 \mathrm{I} x(r 0.72$; P O.0I).

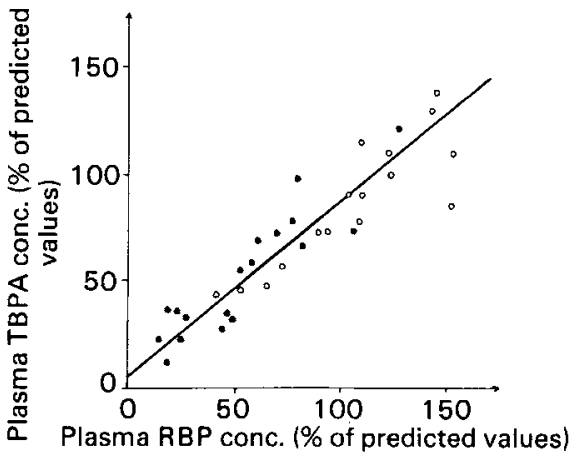

Fig. 4. Plasma thyroxin-binding pre-albumin (TBPA) v. plasma retinol-binding protein (RBP) before starting total parenteral nutrition. (O), Non-cancer patients $(n \mathrm{I} 8) ;(\bigcirc)$, cancer patients $(n \mathrm{I} 6) \cdot y=6 \cdot 04+0.8 \mathrm{I} x(r 0.9 \mathrm{I}$; $P$ o.00I).

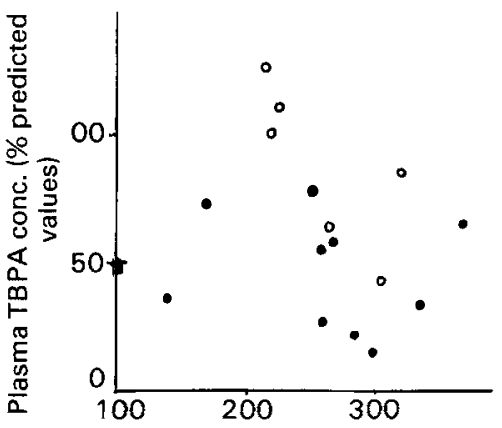

Plasma a- 1 -antitrypsin conc. (mg/100 ml)

Fig. 6. Plasma thyroxin-binding pre-albumin (TBPA) v. plasma $\alpha$-I-antitrypsin. (O), Noncancer patients $(n$ Io); $(O)$, cancer patients $(n$ 7). ( $r 0.04$; not significant.) 
$(r 0.72 ; P<0.01)$ as well as between TBPA and TSF $(r 0.63 ; P<0.01)$ as shown in Figs. 2 and 3 , respectively. A closer correlation $(r 0.91 ; P<0.00 I)$ was found between the plasma levels of both fast turnover visceral proteins TBPA and RBP (Fig. 4). By contrast, no significant correlation could be found between the plasma concentration of TBPA and the level of the acute-phase reactants $\alpha$-I-glycoprotein and $\alpha-\mathrm{I}$-antitrypsin (Figs. 5 and 6 ).

Effect of TPN on the plasma protein concentration of protein-depleted patients with normal renal function. The modifications induced by I week of TPN on the plasma visceral protein level of protein-depleted patients is shown in Fig. 7. A rapid and marked rise was observed for the fast turnover proteins TBPA and RBP. The TSF level tended to rise while albumin concentration remained unchanged.

The effect of $5 \mathrm{~d}$ of TPN on the plasma concentration of visceral and acutephase proteins is presented in Table 2 . Previously depressed TBPA and RBP levels reached the normal range within this short period of TPN. A moderate rise in TSF concentration was observed while albumin and acute-phase reactant levels were not significantly modified.

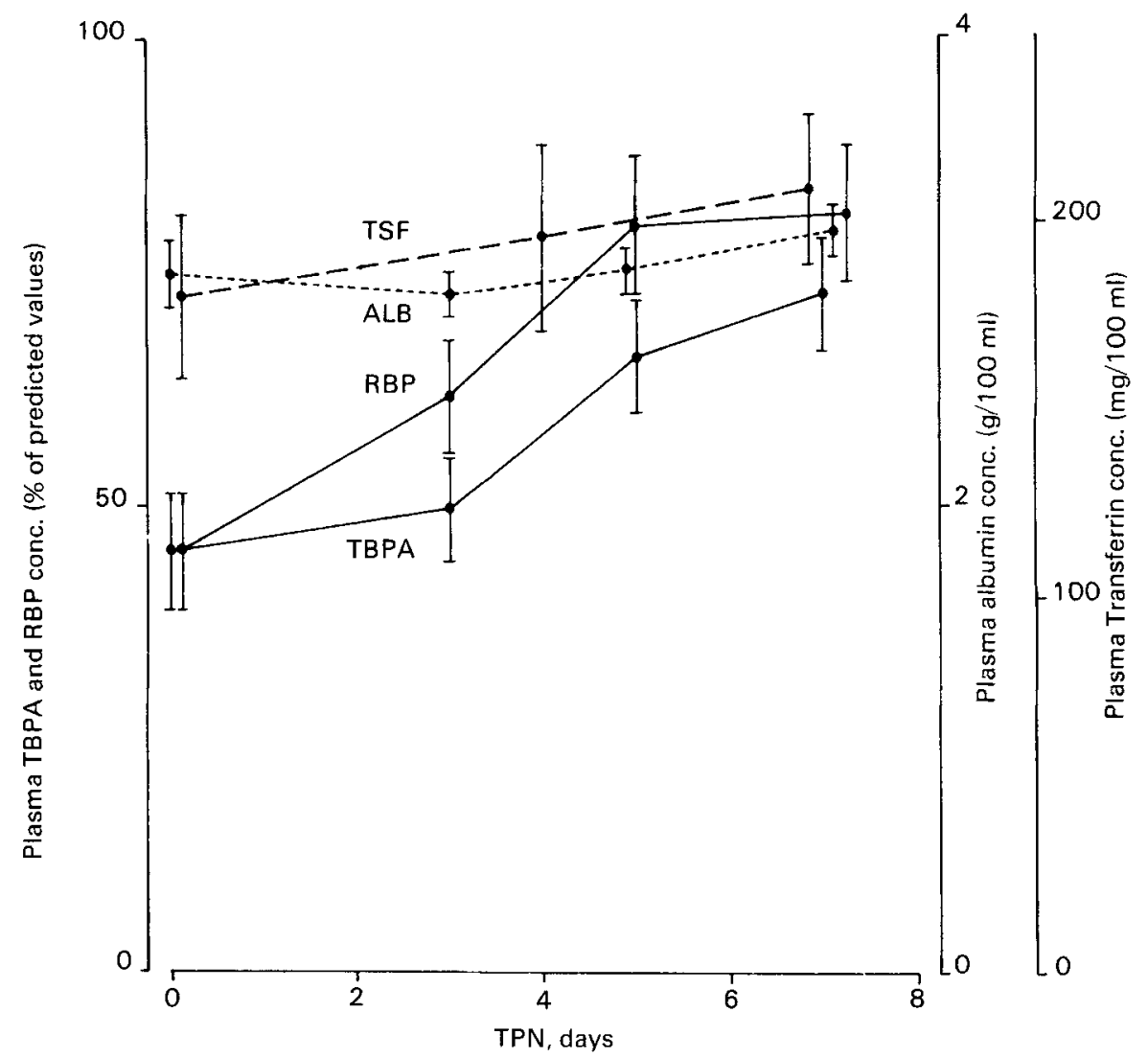

Fig. 7. Effect of total parenteral nutrition (TPN) on the plasma proteins of twelve non-cancer patients. TSF, transferrin; ALB, albumin; RBP, retinol-binding protein; TBPA, thyroxin-binding pre-albumin. 
Table 2. Effect of total parenteral nutrition (TPN) on plasma protein level

Plasma protein

Albumin (g/l)

Transferrin (mg/ $/ 00 \mathrm{ml})$

Thyroxin-binding pre-albumin

(\% predicted value)

Retinol-binding protein

(\% predicted value)

$\alpha$-I-Glycoprotein $(\mathrm{mg} / \mathrm{ro0} \mathrm{ml})$

$\alpha-\mathrm{I}-$ Antitrypsin (mg/roo ml)

$\overbrace{\begin{array}{c}\text { Mean } \\ 29 \cdot 5 \\ 189\end{array}}^{\text {Before TPN }} \begin{gathered}\text { I.4 } \\ 26\end{gathered}$

$\begin{array}{rr}46 \cdot 4 & 5 \cdot 7 \\ 50 \cdot 5 & 6 \cdot 8 \\ 73 \cdot 1 & 7 \cdot 6 \\ 276 & 21\end{array}$

\begin{tabular}{|c|c|c|}
\hline \multicolumn{2}{|c|}{ After $5 \mathrm{~d}$ of TPN } & \multirow[b]{2}{*}{$P$} \\
\hline Mean & SEM & \\
\hline $29 \cdot 6$ & 0.9 & NS \\
\hline 229 & 21 & $<0.05$ \\
\hline $8 I \cdot 8$ & $6 \cdot 5$ & $<0.01$ \\
\hline $\begin{array}{l}97.0 \\
80.3\end{array}$ & $\begin{array}{l}7.6 \\
6.0\end{array}$ & $<0.01$ \\
\hline 303 & 16 & NS \\
\hline
\end{tabular}

NS, not significant.

Effect of TPN on the plasma protein concentration of protein-depleted patients with acute renal failure. The effect of TPN (containing only essential amino acids plus arginine and histidine as nitrogen intake) on the plasma protein concentration of nine patients with acute renal failure but preserved diuresis volume is shown in Table 3. A significant increase in TBPA concentration was observed after $3 \mathrm{~d}$ of TPN and persisted throughout the period of the study. A slight elevation in TSF concentration occurred after $6 \mathrm{~d}$ of TPN. The plasma level of the other proteins remained unchanged.

The effect of TPN on the plasma protein concentration of five patients with acute renal failure requiring recurrent dialysis is shown in Table 4. An increase in the plasma concentration of TBPA was observed after $6 \mathrm{~d}$ of TPN while the level of the other measured proteins remained unchanged throughout the $12 \mathrm{~d}$ period of this study.

Effect of surgery on plasma proteins. As shown in Fig. 8, an elective operation induced a marked rise in the plasma level of the acute-phase reactants that was subsequently followed by a progressive decline occurring after the $4^{\text {th }}$ post-

Table 3. Plasma protein concentration during total parenteral nutrition (TPN) in nine patients with acute renal failure and preserved diuresis

Plasma proteins

Albumin (g/l)

Transferrin (mg/100 ml)

Thyroxin-binding pre-albumin $(\mathrm{mg} / \mathrm{r} 00 \mathrm{ml}$ )

$\alpha$-I-Glycoprotein $(\mathrm{mg} / \mathrm{ro0} \mathrm{ml}$ )

$\alpha-\mathrm{I}$-Antitrypsin (mg/roo ml)

$\mathrm{C}$-reactive protein $(\mathrm{mg} / \mathrm{r} 00 \mathrm{ml})$

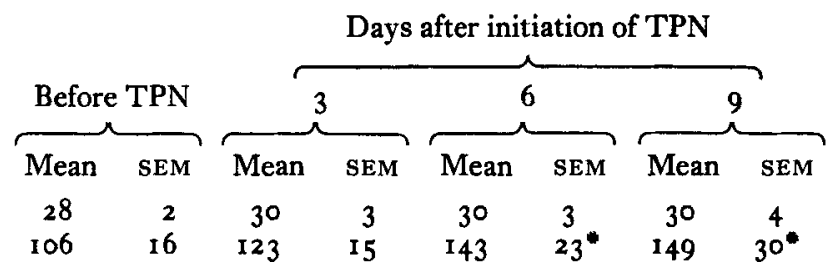

$\begin{array}{llllllllllll}10.7 & 1.7 & 13.5 & 2.3^{*} & 20.0 & \mathrm{I} \cdot 8^{* *} & 18.1 & \mathrm{I} \cdot 8^{* *}\end{array}$

$\begin{array}{llllllll}144 & 22 & 155 & 21 & 142 & 19 & 131 & 24\end{array}$

$\begin{array}{llllllll}716 & 127 & 717 & 198 & 594 & 192 & 665 & 15^{8}\end{array}$

$\begin{array}{llrrrrrr}14 & 4 & \text { I } & 4 & \text { I3 } & 3 & \text { I0 } & 2\end{array}$

$* P<0.05, * * P<0.01$ compared to initial values. 
Table 4. Plasma protein concentration during total parenteral nutrition (TPN) in five patients with acute renal failure requiring recurrent dialysis

Plasma proteins

Albumin $(\mathrm{g} / \mathrm{l})$

Transferrin $(\mathrm{mg} / \mathrm{roo} \mathrm{ml})$

Thyroxin-binding pre-albumin

$$
\text { (mg/roo ml) }
$$

$\alpha-\mathrm{I}-$ Glycoprotein $(\mathrm{mg} / \mathrm{ro0} \mathrm{ml})$

$\alpha-\mathrm{I}-$ Antitrypsin (mg/roo ml)

C-reactive protein $(\mathrm{mg} / \mathrm{r} 00 \mathrm{ml})$

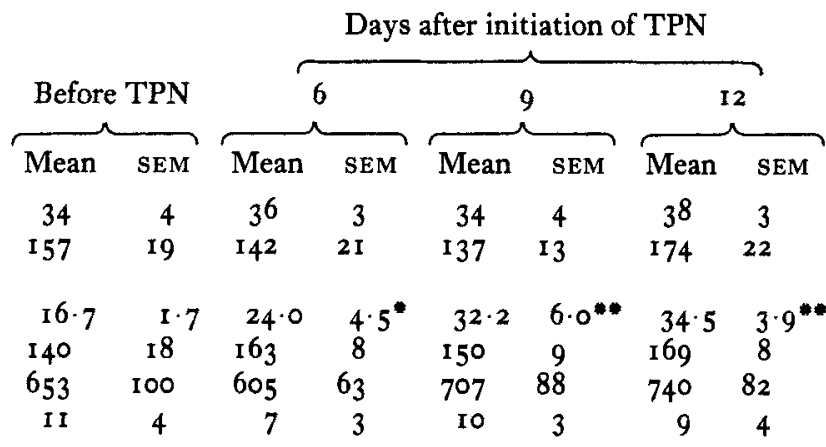

*P<0.05, ** $P<0.01$ compared to initial values.

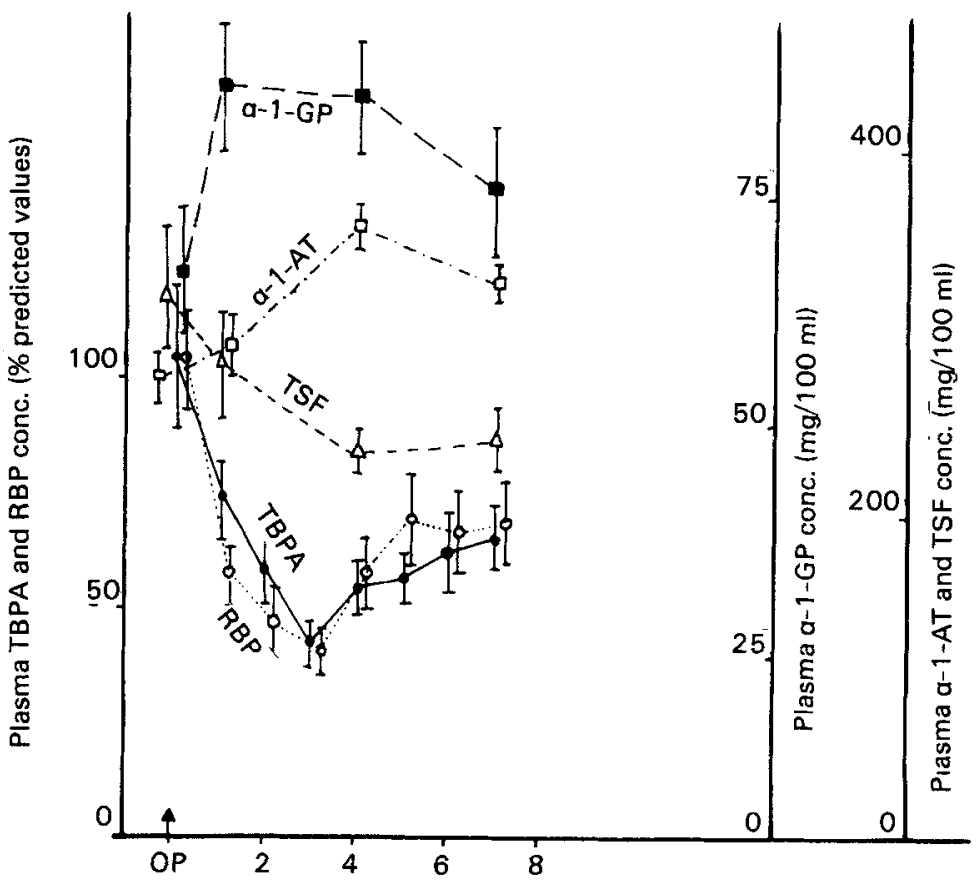

Post-operative days

Fig. 8. Effect of elective surgery on plasma proteins ( $n$ I0). $\alpha-1-G P, \alpha-I$-glycoprotein; $\alpha-I-A T$, $\alpha-1$-antitrypsin; TSF, transferrin; TBPA, thyroxin-binding pre-albumin; RBP, retinol-binding protein. 
operative day. By contrast, TBPA and RBP levels rapidly dropped (by about $50 \%$ of the initial values) until the 3 rd post-operative day; afterwards, they tended to return towards the normal range. Plasma TSF concentration decreased in the early post-operative period and remained stable after the $4^{\text {th }}$ post-operative day.

Plasma albumin concentrations observed during the post-operative course followed a pattern very similar to the one recently reported by Moore \& Clark (1982).

The post-operative evolution of plasma proteins of patients having undergone emergency surgery without post-operative complications is presented in Fig. 9, and compared with plasma proteins of patients before and after an elective operation. Except for the plasma concentrations of acute-phase reactants that tended to reach higher values in the emergency cases, the levels of visceral proteins are very similar in both groups.

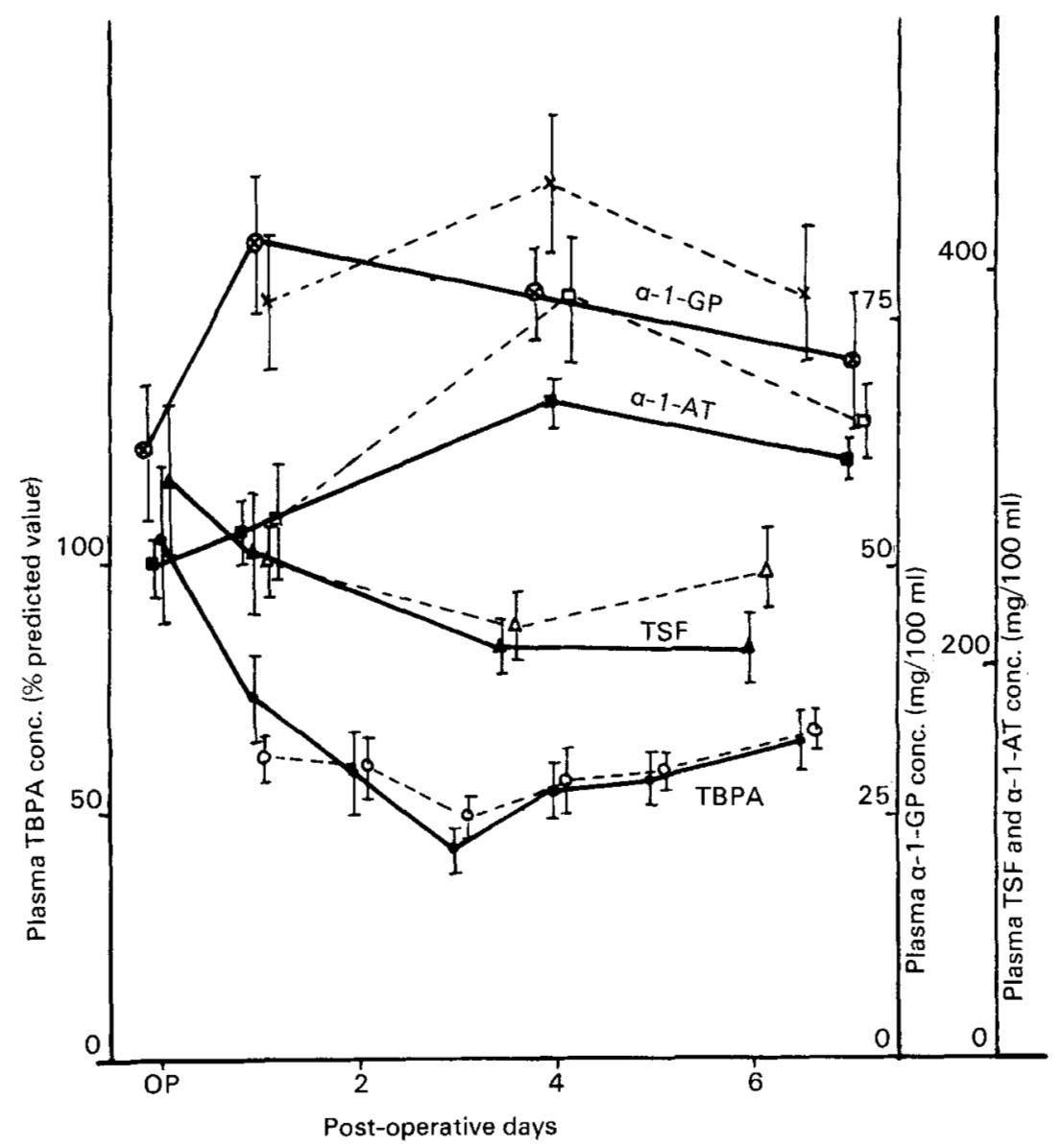

Fig. 9. Effect of emergency $(---)\left(\begin{array}{ll}n & \mathrm{I} 2\end{array}\right) v$. elective $(-)(n$ Io) surgery on plasma proteins. $\alpha-I-G P, \alpha-I-g l y c o p r o t e i n ; \alpha-I-A T, \alpha-I-a n t i t r y p s i n ; T S F$, transferrin, TBPA, thyroxin-binding pre-albumin. 
Two patients who developed an infectious complication in the immediate postoperative period following emergency surgery showed a strikingly different evolution of plasma proteins (Fig. Io). In these patients, the acute-phase reactants were still rising after the 6th post-operative day while the TBPA and RBP levels continued to decline. The TSF level showed a pattern very similar to the one observed in the patients with an uncomplicated post-operative course.

\section{Discussion}

Inter-relation between plasma protein concentrations. A significant positive correlation has been found in a group of non-injured patients between the plasma concentration of the four visceral proteins considered for the present work. However, the correlation coefficient $r$ was found to be high enough to allow a correlation between individual subjects only when the fast turnover proteins,

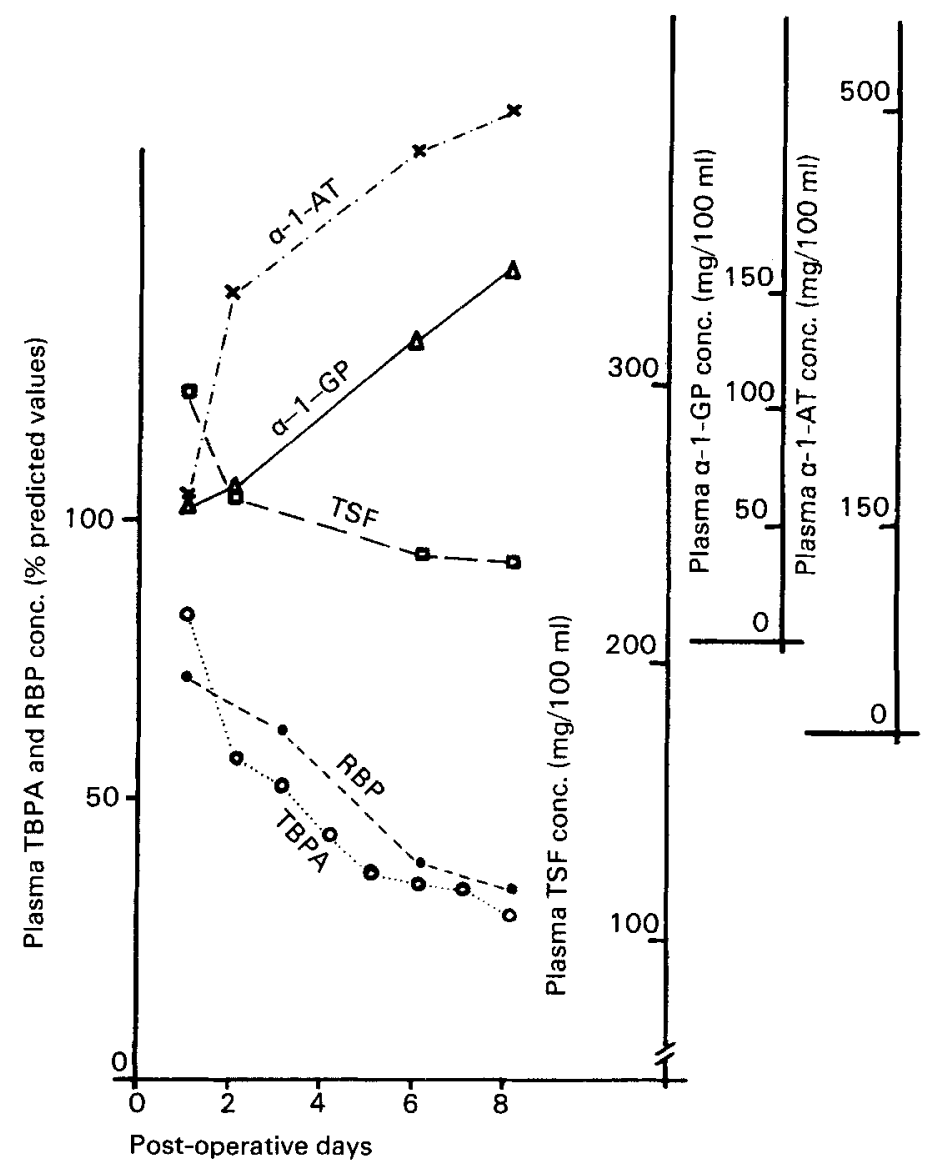

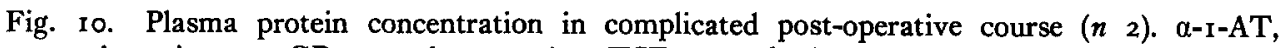
$\alpha$-1-antitrypsin; $\alpha$-1-GP, $\alpha$-1-glycoprotein; TSF, transferrin; RBP, retinol-binding protein; TBPA, thyroxin-binding pre-albumin. 
TBPA and RBP, were considered. The correlation between the plasma levels of TBPA and the slow turnover visceral proteins, albumin and TSF, was not as close and its use should therefore be restricted to comparisons between groups of subjects. As shown in Fig. 2, a group of four non-cancer patients presented particularly low TBPA levels in comparison with albumin concentrations. All four patients had an inflammatory bowel disease. The discrepancy between TBPA and albumin levels could be explained either by a sudden deterioration of the nutritional status not reflected by the slower changes in albumin concentration or by the exacerbation of the inflammatory process. This latter hypothesis seems less likely since no correlation was observed in the seventeen patients studied between the concentrations of TBPA and acute-phase reactants.

Effect of TPN on plasma proteins in protein-depleted subjects. Despite the transient plasma dilution due to the fluid load provided by TPN, a rise in the plasma concentration was observed for three visceral proteins. The rapidity of the response was directly related to the turnover rate of the proteins. The absence of modification in the levels of acute-phase reactants rules out the possibility of resolved inflammatory process and supports the hypothesis of a direct nutritional effect of parenteral alimentation on visceral protein synthesis. We have repeatedly observed in patients followed for prolonged periods (unpublished personal data) that the early and marked changes in TBPA concentrations are adequate for predicting later and slower rises in albumin concentration.

TPN with essential amino acids, glucose and lipids was adequate for inducing a rapid rise in TBPA levels in both groups of patients with acute renal failure. The stable inflammatory conditions were also assessed in these patients by the absence of change in the concentrations of acute-phase reactants. An improvement in nitrogen balance has previously been reported in patients with acute renal failure receiving TPN with essential amino acids (Wilmore \& Dudrick, I969; Abel et al. 1973). However, it was impossible in these studies to separate the influence of the nitrogen intake on protein synthesis from the inhibitory effect of glucose and insulin on muscle catabolism. Our findings suggest that TPN with essential amino acids can stimulate the synthesis of some proteins.

TBPA concentrations seem abnormally high in the group of patients with acute renal failure and impaired diuresis (Table 4 ) when compared to the other groups of patients. This is in agreement with a previous observation in patients with chronic renal failure (Young et al. 1975) and suggests some role for the kidneys in TBPA catabolism; however, we have shown in a previous study that dialysis does not affect TBPA levels (Carpentier et al. 1981). This means that TBPA concentration should not be used as an absolute value in patients with acute renal failure. Nevertheless, the evolution of TBPA could still be suitable for assessing the efficacy of nutritional support in stable conditions.

Effect of surgery on plasma protein concentration. It should be pointed out that the model of surgical operation used in the present study does not allow us to clearly separate the effect of injury from the influence of several days of partial starvation. After an injury, the plasma concentration of proteins is influenced by 
many non-specific factors such as direct protein losses, total body water retention, increased extracellular/intracellular water ratio, increased capillary membrane permeability to some proteins, as well as specific factors such as a modification in the synthesis/breakdown balance for each protein. These factors have been particularly well investigated in relation to the metabolism of albumin (Moore \& Clarke, 1982). In the early post-operative period, we have observed in both groups of surgical patients a very marked increase in the plasma level of acute-phase reactants concomitant with a sharp drop in the concentration of fast turnover visceral proteins. These changes in TBPA and RBP concentrations cannot be entirely explained by non-specific factors. The results of the present study suggest that the metabolic response to injury resets the priority of protein synthesis by the liver towards the production of acute-phase reactants at the expense of, at least some, visceral proteins. Therefore, the effect of injury on plasma visceral proteins appears to be much more dependent on inflammatory than nutritional conditions. Indeed, we have observed very similar post-operative variations of plasma protein concentration in a group of patients who received TPN after abdominal surgery (unpublished data). However, a retrospective comparison of post-operative TBPA concentration was recently made between two groups of five patients each undergoing surgery for rectal cancer; these groups were as well as possible matched for age, sex, grade of the tumour, type of operation and post-operative complications. TPN was infused at least $5 \mathrm{~d}$ before and I week after surgery in group A and only in the post-operative course in group B. TBPA concentrations were normal in both groups before surgery but decreased significantly less (80 $v .48 \%$ of the predicted values; $P<0.01$ ) and returned much faster towards normal values in group A than in group B. A well-controlled randomized study is needed to assess whether pre-operative TPN can help to maintain post-operative levels of visceral proteins in the normal range.

\section{Conclusions}

The determination of plasma concentration of various proteins is an easy procedure that can be repeatedly performed in a patient. The information provided by these measurements is more specific than the one given by total body nitrogen or nitrogen balance. However, the plasma concentration of a protein is not only the result of the balance between synthesis and breakdown but is also markedly affected by changes in the space of distribution.

The plasma concentration of rapid turnover visceral proteins is positively correlated with the level of slow turnover visceral proteins that are currently used in nutritional assessment.

When TPN is administered to protein-depleted non-injured patients, the rapidity and the extent of the elevation in the plasma level of different visceral proteins is related to the turnover rate.

The plasma concentration of rapid turnover visceral protein appears to be a very sensitive parameter for indicating the efficiency of a nutritional therapy. However, 
the level of these proteins is highly affected by the inflammatory response. Therefore, their use as nutritional indices should be restricted to investigating patients in stable inflammatory conditions.

The authors wish to thank Drs Y. Ingenbleek, M. Reynaert and J. Duchateau for their appreciated collaboration as well as Mrs I. Sprangers and F. Champt for their skilful technical assistance.

This study was approved by The Ethical Committee of the Free University of Brussels and was supported by FRSM (Belgium) grant no. 3.4555.8I and by Travenol and Kabivitrum Laboratories.

\section{REFERENCES}

Abel, R. M., Beck, C. H., Abbott, W. M., Ryan, J. A. Jr, Barnett, G. O. \& Fischer, J. E. (1973). New Engl. J. Med. 288, 695 .

Carpentier, Y. A., Reynaert, M., Ingenbleek, Y., Barthel, J. \& Vandenbrouck, J. M. (1981). F. parent. ent. Nutr. 5, 359 .

Cooper, E. H. \& Ward, A. M. (1979). Invest. Cell Path. 2, 293.

Fleck, A. (I981). Ann. clin. Biochem. 18,6r.

Goodman, D. S. (1979). Fedn Proc. Fedn Am. Soc. exp. Biol. 38, 250 r.

Ingenbleek, Y., Van Den Schriek, H. G., De Nayer, P. \& De Visscher, M. (1975). Clin. Chim. Acta $63,6 \pi$.

Large, S., Neal, G. \& Glover, J. (I980). Br. F. Nutr. 43, 393.

Milano, G., Cooper, E. H., Goligher, J. C., Giles, G. R \& Munro, N. A. (1978). F. Natn. Cancer Inst. 6r, 687 .

Moore, P. J. \& Clark, R. G. (I982). Br. F. Surg. 69, I 40.

Mullen, J. L., Buzby, J. P., Matthews, D. C., Smale, B. F. \& Rosato, E. F. (1980). 192, 604.

Munro, H. N. (editor) (1970). In Mammalian Protein Metabolism, vol. 4, p. 382. New York: Academic Press.

Pawanda, M. C. \& Beisel, W. R. (1982). Am. F. clin. Nutr. 35, 762.

Ramsden, D. B., Prince, H. P., Burr, W. A., Bradwell, A. R., Black, E. G., Evans, A. E. \& Hoffenberg, R. (1978). Clin. Endocr. (Oxf.) 8, 109.

Rask, L., Anundi, H., Bohme, J., Eriksson, V., Fredriksson, A., Nilsson, S. F., Ronne, H., Vahlquist, A. \& Peterson, P. A. (1980). Scand. F. clin. Lab. Invest. 40, suppl. 154, 45.

Shetty, P. S., Watrasiewicz, K. E., Jung, R. T. \& James, W. P. T. (1979). Lancet. ii, 230.

Surks, M. I. \& Oppenheimer, J. H. (1964). F. Clin. Endocr. 24, 794.

Wilmore, D. W. \& Dudrick, S. J. (1969). Arch. Surg. 99, 669.

Young, G. A., Collins, J. P. \& Hill, G. L. (1979). Am. f. clin. Nutr. 32, 1192.

Young, G. A., Keogh, G. B., \& Parsons, F. M. (1975). Clin. Chim. Acta 61, 205. 